\title{
Foodborne Disease in Kenya: County- level Cost Estimates and the Case for Greater Public Investment
}

Vivian Hoffmann and Siddhartha Baral

\section{Introduction}

The right to safe food is enshrined in the Kenyan constitution. Through their jurisdiction over matters of agriculture - specifically crop and animal husbandry, abattoirs, and veterinary services - and health, including the licensing and control of undertakings that sell food to the public, county governments in Kenya have a critical role to play in meeting this obligation to their citizens.

Food safety has 'public good' characteristics and requires sufficient public investment. Appropriate budgetary allocation for food safety investments, requires that county governments understand the current costs of foodborne disease (FBD), as well as the gains they could achieve through improved public capacity to manage food safety risks. However, due to limited availability of data attributing ill-health to specific causes, as well as general under-reporting of health complaints to medical systems, estimates of the health and economic costs of foodborne disease (FBD) in Kenya exist only at the national level. In the context of devolution, the lack of county-specific estimates constitutes a barrier to effective policy-making regarding the control of FBD. In this study, we combine recent national estimates of the health burden attributable to FBD from the World Health Organization (WHO) with county-level data on diarrhea rates to estimate the health and economic burdens of FBD for Murang'a, Laikipia, Nakuru, Nyandarua, and Nairobi counties. 
We then summarize recent evidence on the link between public investment in food safety capacity and foodborne disease burden in low and middle-income countries. Based on this evidence and a comparison of the costs of FBD versus current county allocations to food safety, we argue that additional funding to manage food safety risks in the five counties reviewed is required to address these risks.

In the following section, we describe the importance of diarrheal disease as the sub-category of foodborne disease with the greatest global health impact. In Section 3, we present estimates of health burden and associated productivity cost of FBD at the county level, and compare this against the budget allocations to management of food safety by risk Murang'a, Laikipia, Nakuru, Nyandarua, and Nairobi counties.

Household-level correlates of diarrheal illness, which confirm the link between consumption of high-risk foods and illness, are described in Section 4. In Section 5, we summarize recent evidence on the link between public investments in the management of food safety risks and health outcomes. In the final section we conclude that based on the evidence available, increased public investment in food safety at the county level is likely to be justified.

\section{Foodborne diarrheal disease}

At 549 million cases per year, pathogens transmitted by food represent 90 percent of the global burden of diarrheal diseases (Havelaar et al., 2015). ${ }^{1}$ Diarrheal FBDs accounted for $55 \%$ of FBD related premature deaths and $54 \%$ of loss in FBD associated Disability-Adjusted Life Years or DALYs (Havelaar et al., 2015). ${ }^{2}$ Taking a different approach, some studies on the cost of care and illness, one study pegged the cost of illness for food borne diarrhea at KSH 1,034 in Nigeria and KSH 4,136 for Ethiopia per case (Grace et al., 2018 as cited in Jaffee et al., 2018). ${ }^{3}$

While children under 5 years of age represent 9 percent of the global population, they account for 38 percent of all cases of foodborne illness, 30 percent of premature deaths, and 40 percent of the DALYs (Jaffee et al., 2018). Such public health costs translate into economic costs through channels such as the costs of care, lost economic productivity among caregivers and, in the case of adult illnesses, among those who fall ill.

Diarrheal disease is strongly associated with stunting among children. These diseases are spread through ingestion of microorganisms found in the fecal matter of infected people and animals. Vegetables can become contaminated with these microorganisms if untreated human or

\footnotetext{
${ }^{1}$ In addition to foodborne transmission, these pathogens may also be transmitted via contaminated water, soil, and direct contact with infected animals and people.

${ }^{2}$ The disability-adjusted life-year (DALY) is a common metric used by health researchers and policy makers to describe the burden of ill-health. One DALY can be thought of as one lost year of healthy life. Each year that a person dies before their potential lifeexpectancy is equal to one DALY, and each year lived with a health condition is equal to a partial DALY, with a standard value assigned to each health condition based on the quality of life with that condition.

${ }^{3}$ USD to KSH conversion employs 2017 yearly average exchange rate of USD 1 to $103.4 \mathrm{KSH}$.
} 
animal waste is used to fertilize crops or if sewage runoff or animal waste enters bodies of water used for irrigation. Meat and meat products can be contaminated if the animals themselves are infected, or if fecal matter from the animal comes into contact with products to be consumed. Any type of food can become contaminated if someone who handles food - be it the farmer who grows it, the broker who trades it, the vendor who sells it, or the consumer who prepares and stores it - has not washed their hands thoroughly after using the toilet, or has shaken hands with someone else who has failed to practice good hygiene. In addition, if food is uncovered, flies can spread microorganisms from the environment (where animal and human feces may be present) to food.

While water and person to person contact are also important routes of transmission, a major pathway of diarrheal pathogens into the body is through contaminated food. One study attributed $25 \%$ of the stunting burden to the repeated diarrheal episodes (Checkley et al., 2008).

As physical stunting also implies a failure to reach cognitive potential, the impacts of diarrheal disease longer-term implications beyond the near-term health and economic costs of foodborne illness. Diarrhea is further disproportionately concentrated in African and Asian countries, with just 15 such countries, including Kenya, accounting for $53 \%$ of total global episodes (Walker et al., 2013).

\section{Quantifying the burden of diarrheal foodborne disease in 5 Kenyan counties}

In this section, we estimate the burden of diarrheal and overall foodborne disease in Kenya as a whole, and the five counties of interest for this report. We begin by estimating the proportion of diarrhea transmitted through food, using findings from the $2015 \mathrm{WHO}$ report on the global burden of FBD (World Health Organization, 2015). As data specific to Kenya is not available, we use regional estimates for Africa as a whole. For each pathogen, we multiply the African regional estimate of the number of DALYs per 100,000 people (column 2), by the proportion of transmission estimated to be foodborne in the region (column 3 ). This gives the values in column 4, which are then summed, and divided by the DALY burden of diarrheal disease per 100,000 (col 2, row b), plus the burden of invasive diseases of which diarrhea is a symptom (col 2 , rows $m$ and $n$ ). Through this calculation, we estimate that the total proportion of diarrheal disease in Africa transmitted through food is $29 \%$. 
Table 1: Diarrheal disease attributable to food sources in sub-Saharan Africa

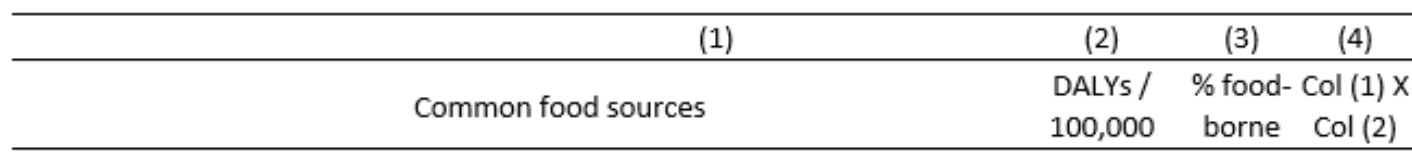

(a) Diarrheal disease (all)

687

Diarrheal pathogen transmitted through food

(b) Campylobacter spp. Raw and undercooked poultry, unpasteurized

milk, poorly washed fruits and vegetables

$\begin{array}{lll}70 & 0.57 \quad 39.9\end{array}$

(c) Cryptosporidium spp. Raw/under-cooked food, unpasteurized milk, food contaminated with infected human feces

$\begin{array}{lll}13 & 0.15 & 2.0\end{array}$

(d) Entamoeba histolytica

food contaminated with infected human

feces

$\begin{array}{lll}5 & 0.3 & 1.5\end{array}$

Undercooked beef, unpasteurized

(e) Enteropathogenic E. coli

milk and juice, raw fruits and

$0.29 \quad 40.6$

(f) Enterotoxigenic E. coli vegetables

food contaminated with infected human feces

109

$0.33 \quad 36.0$

(g) Giardia spp.

food contaminated with inifected human or animal feces

$\begin{array}{lll}0.8 & 0.11 \quad 0.1\end{array}$

food contaminated by feces or vomit of

(h) Norovirus infected person, fruits and vegetables contaminated in the field

$81 \quad 0.15 \quad 12.2$

Eggs, poultry, meat,

(i) Non-typhoidal Salmonella unpasteurized milk or juice, enterica cheese, contaminated raw fruits

$\begin{array}{lll}89 & 0.46 \quad 40.9\end{array}$

(j) Shigella spp. and vegetables

(k) Shiga toxin-producing $E$. coli

food contaminated with human feces

(I) Vibrio cholerae

raw and undercooked meat and poultry

0.05

$0.43 \quad 0.0$

Invasive diseases that cause diarrhea

(m)Salmonella enterica Typhi* -

Uncooked foods contaminated by the virus,

(n) Hepatitis A* cooked foods that are not heated to temperatures capable of killing the virus during preparation

Proportion of all diarrheal disease that is food-borne

Note: Information in Col 1 is obtained from the web fact-sheets of The Centers for Disease Control and Prevention (CDC), USA. 
Next, we apply the percentage of diarrheal disease estimated to be foodborne to diarrheal disease rates calculated from the most recent publicly available round of the Kenya Demographic and Health Survey (KDHS), a nationally and regionally representative survey conducted by the Kenya National Bureau of Statistics (Kenya National Bureau of Statistics, 2015). While the $\mathrm{KDHS}$ is not representative at the county level, the data contain more observations on child diarrhea per county than any other available source.

As shown in Table 2, over $15 \%$ of Kenyan children under 5 years of age had suffered diarrhea within the two weeks prior to being surveyed, according to the child's primary caregiver. At $15.7 \%$, the predominantly urban county of Nairobi has the highest diarrhea rate among the five counties on which this report is focused. While not all diarrheal disease results from foodborne pathogens, we estimate the likelihood of foodborne diarrheal disease over the past two weeks using the estimate of $29 \%$ as calculated in Table 1 . Using this approach, we find that $4.4 \%$ of Kenyan children under five years of age suffered from foodborne diarrhea over the two weeks preceding the survey. Among the counties studied, the estimated rate of foodborne diarrhea ranges from $3.2 \%$ (Murang'a) to $4.6 \%$ (Nairobi).

Using the most recent available estimate of the number of diarrheal child deaths per 1000 live births for Kenya (UNICEF, 2018), we extrapolate county-level diarrheal death rates per 1000 based on county-specific diarrhea rates relative to the national average. ${ }^{4}$ We then multiply this rate by population figures found in County Integrated Development Plans and reported by the National Council for Population and Development (2015) for Kenya as a whole ${ }^{5}$ (Col 5), and divide by five to come to an estimate of the annual number of child deaths due to foodborne diarrheal disease (Col 7). We conclude that 1,328 children die each year in Kenya due to diarrheal FBD. Across the counties studied, the number of child deaths ranges widely, mostly based on population. In Nairobi, the number of children who die each year due to diarrheal FBD is estimated at 134, while Laikipia, which has a smaller population, experiences an estimated 11 such deaths per year. Details of the calculations behind this table are included in Appendix Table 1.

Estimating the overall health burden per county due to all foodborne diseases, including those for which the symptoms do not include diarrhea, requires the assumption that the incidence of these other diseases varies across counties in proportion to diarrheal disease. Given that general food hygiene practices are likely to reduce both diarrheal and microbial risks, which account for the vast majority of FBD, in roughly equal measure, we apply this assumption to come up with the estimates shown in Col 8 through Col 10 of Table 2.

\footnotetext{
${ }^{4}$ For each county, we multiply the Kenyan rate of 3 child deaths per 1000 live births by the ratio of that county's diarrheal rate (Table 2 , Col 1) over the country-wide diarrheal rate of $15.1 \%$.

${ }^{5}$ County-level estimates for 2018 are used. A national estimate is available only for 2017 ; we multiply this by the $2.9 \%$ annual growth rate reported by NCFP (2015) to come to an estimate of the national population in 2018.
} 
Table 2: The cost of foodborne disease in Kenya

\begin{tabular}{|c|c|c|c|c|c|c|c|c|c|c|c|c|}
\hline & (1) & (2) & (3) & (4) & (5) & (6) & (7) & (8) & (8) & (9) & (10) & (11) \\
\hline County & $\begin{array}{c}\text { Child had } \\
\text { diarrhea } \\
\text { past } 2 \text { weeks } \\
\text { (\%) }\end{array}$ & $\begin{array}{l}\text { Number } \\
\text { of obs. }\end{array}$ & $\begin{array}{c}\text { Extrapolated \% } \\
\text { of foodborne } \\
\text { diarrhea / } 2 \\
\text { weeks }\end{array}$ & $\begin{array}{c}\text { Extrapolated } \\
\text { diarrheal } \\
\text { child deaths } \\
\text { / year / } 1000\end{array}$ & $\begin{array}{c}\text { County } \\
\text { population, } \\
2018 \text { (CIDPs) }\end{array}$ & $\begin{array}{l}\text { County } \\
\text { population } \\
\text { under } 5 \\
\text { (CIDPs) }\end{array}$ & $\begin{array}{c}\text { Annual } \\
\text { under-5 } \\
\text { deaths due } \\
\text { to diarrheal } \\
\text { FBD }\end{array}$ & $\begin{array}{l}\text { DALYs per } \\
\text { 100,000 due } \\
\text { to FBD }\end{array}$ & $\begin{array}{l}\text { Estimated } \\
\text { total DALYs } \\
\text { due to FBD }\end{array}$ & $\begin{array}{c}\text { Estimated } \\
\text { annual cost } \\
\text { of FBD } \\
\text { (million KSH) }\end{array}$ & $\begin{array}{l}\text { Loss as a } \% \\
\text { of county or } \\
\text { national GDP }\end{array}$ & $\begin{array}{l}\% \text { stunted } \\
\text { children }\end{array}$ \\
\hline Murang'a & $10.9 \%$ & 227 & $3.2 \%$ & 2.16 & 1128177 & 141002 & 18 & 822 & 9275 & 1684 & 0.82 & $19.7 \%$ \\
\hline Laikipia & $13.7 \%$ & 291 & $4.0 \%$ & 2.73 & 491927 & 72138 & 11 & 1036 & 5098 & 923 & 1.04 & $26.8 \%$ \\
\hline Nakuru & $11.8 \%$ & 337 & $3.4 \%$ & 2.35 & 1603325 & 319642 & 44 & 893 & 14319 & 4851 & 0.89 & $29.3 \%$ \\
\hline Nyandarua & $11.9 \%$ & 235 & $3.5 \%$ & 2.36 & 712595 & 102417 & 14 & 897 & 6391 & 2077 & 0.90 & $28.8 \%$ \\
\hline Nairobi & $15.7 \%$ & 418 & $4.6 \%$ & 3.13 & 4941708 & 735671 & 134 & 1190 & 58805 & 22995 & 1.19 & $17.1 \%$ \\
\hline Other counties & $15.3 \%$ & 13165 & $4.5 \%$ & 3.05 & 38250468 & 6221164 & 1107 & 1160 & 443599 & 68470 & 1.16 & $26.4 \%$ \\
\hline Kenya & $15.1 \%$ & 14673 & $4.4 \%$ & 3.00 & 47128200 & 7592034 & 1328 & 1140 & 537261 & 101517 & 1.14 & $25.5 \%$ \\
\hline
\end{tabular}

Note: In Col 1, diarrheal rate is representative at the national level but not at the county level (DHS provides representative figures up till the regional or formerly provincial level). In Col. 6, overall population under 5 employs the national demographic structure from Kenya where $16.1 \%$ of the population are under 5 . In Col 8 , Kenya-wide estimate is obtained from Steven Jaffee's calculation (S. Jaffee, personal communication, January 9, 2019). County-wide estimates are calculated based on relative prevalence of diarrheal disease. In Col 10 for each row, annual cost is calculated as the product of total DALYs from Col. 9 and Kenya's county level GDP obtained using counties' relative contributions to GDP (Kenya National Bureau of Statistics, 2019). 
We translate the WHO estimate of 1,140 DALYs due to FBD per 100,000 people in Kenya (S. Jaffee, personal communication, January 9, 2019), to county level DALY burdens by scaling the national figure by the child diarrhea rate in each county relative to the national average, and then multiplying by county population (Col 8). At 1,190, Nairobi has the highest rate of DALYs due to FBD per 100,000, while Murang'a has the lowest (822). Multiplying these rates by population, we calculate county-wise FBD health burdens ranging from 5,098 DALYs in Laikipia to 58,805 DALYs in Nairobi.

Since each DALY represents a year lost to illness, disability, or death, this health burden can be converted to an economic cost by multiplying DALYs by the gross domestic product (GDP) per capita.This is the approach taken by Jaffee et al. (2018). Multiplying DALYs by GDP per capita, we find that the total economic loss due to FBD in Kenya is equivalent $1.14 \%$ of national GDP. Applying county-level GDP per capita to the county-level DALY estimates, we further find that Nairobi's economic losses are proportionally highest at $1.19 \%$ of county GDP, with Murang'a registering the lowest proportional loss, at $0.82 \%$ of the county's economic activity (Col 10$)$.

In addition to the health burden caused by foodborne illness, disruptions in food markets associated with FBD outbreaks and perceptions of food-borne risks include negative price effects and reduced investment (Hassouneh et al., 2012; Popovic, Radovanov, \& Dunn, 2017). By shifting consumer preferences away from relatively riskier but nutritious fresh produce to less risky but also less nutritious foods, food safety failures can lead to negative effects on nutrition (Kavle et al., 2015). For counties that depend on agricultural exports either within or outside of Kenya, perceived or real foodborne hazards can lead to heightened scrutiny among foreign and domestic buyers. Impacts on tourism may also be significant. These other costs are not included in the DALY-based estimates presented here, which can thus be considered a lower-bound of the full economic cost.

As can be seen in Table 3, we find a large disparity between the estimated cost of FBD and the amount spent by the national and county governments on management of food safety risk related to dairy and horticulture. While food safety budget on dairy and horticulture at the national level stands at $13 \%$ of the cost of FBD, this figure for Nairobi is only $0.3 \%$. Given that many of the government functions related to management of food safety are the responsibility of county governments, these estimates suggest a need for greater investment in the management of food safety risk at this level. 
Table 3: Comparing FBD costs and food safety budgets

\begin{tabular}{lccccc}
\hline & $(1)$ & $(2)$ & $(3)$ & $(4)$ & $(5)$ \\
\hline & $\begin{array}{c}\text { Estimated } \\
\text { annual cost of } \\
\text { FBD (2017, } \\
\text { million KSH) }\end{array}$ & $\begin{array}{c}\text { Budget } \\
\text { spent on } \\
\text { sairy food } \\
\text { safety } \\
\text { (2017, } \\
\text { million KSH) }\end{array}$ & $\begin{array}{c}\text { Budget spent on } \\
\text { horticulture food } \\
\text { safety (2017, } \\
\text { million KSH) }\end{array}$ & $\begin{array}{c}\text { Budget spent on } \\
\text { food safety (dairy } \\
\text { and horticulture, } \\
\text { 2017, million KSH) }\end{array}$ & $\begin{array}{c}\text { Food } \\
\text { safety } \\
\text { budget as } \\
\text { a of cost } \\
\text { of FBD }\end{array}$ \\
\hline Murang'a & 1593 & 41 & 17 & 58 & 3.6 \\
Laikipia & 873 & 54 & 8 & 61 & 7.0 \\
Nakuru & 4589 & 143 & 14 & 156 & 3.4 \\
Nairobi & 21755 & 69 & 5 & 110 & 0.3 \\
Nyandarua & 1965 & 64 & 46 & 12466 & 5.6 \\
Kenya overall & 96043 & 10717 & 1749 & 13.0 \\
\hline
\end{tabular}

Note: Col 1 deflates the figures reported in Table 2, Col 10 by Kenya's 2018 annual growth rate of $5.7 \%$. Col 2, 3, and 4 are calculated from the adding up the amount spent on all new and recurrent food safety related programs on dairy and horticulture, as estimated by Guthiga, Kirui and Karugia (2019).

\section{Determinants of diarrheal disease among children under 5}

In order to understand the determinants of diarrheal FBD and identify potential points of intervention, we turn to household-level and dietary factors with which diarrheal disease is associated. Given that diarrheal disease disproportionately affects young children, we make use of Kenya DHS data from 2014 to study the factors that help explain the incidence of diarrhea among children under 5 (KNBS, 2015). For households with multiple children under 5 , we use the information associated with the youngest child.

Using this sample, and the primary caregiver's response to the question "Has [child's name] had diarrhea in the past 2 weeks?", we apply multivariate regression analysis to study factors that are known to be associated with diarrheal disease among children. We consider three broad categories of factors that could potentially affect the likelihood of diarrheal disease: child and mother characteristics, foods consumed by children under 2 years of age, and household characteristics.

As younger children are known to be particularly vulnerable to diarrhea, and because dietary data is only available for these children, we present analysis using the sub-sample of children under 2 years of age in Table 4, and for the entire sample in Table 5. We estimate the association between diarrhea and age using a spline regression approach, so that the linear association between age (in months) is allowed differ between those aged up to 12 months, those between 12 and 24 months, and those older than 24 months. We discuss the results of these two sets of analysis jointly. 
Because household wealth level is correlated with many of the risk factors for diarrheal disease we seek to understand, we estimate specifications both omitting (Table 4 columns 1, 2, 5, 6; Table 5 columns 1 and 2) and controlling for (Table 4 columns 3, 4, 7, 8; Table 5 columns 3 and 4) household wealth. Estimates are expected to be stronger when omitting wealth, but we can put greater confidence in associations that remain significant even after controlling for wealth effects. As risk factors may be geographically correlated, we take a similar approach in presenting specifications with (Table 4 columns 2, 4, 6, 8; Table 5 columns 2 and 4) and without (Table 4 columns 1, 3, 5, 7; Table 5 columns 1 and 3) controls for geographical sampling strata. All specifications control for regional differences with indicator variables at the former provincial level.

\section{Child and mother specific characteristics:}

Samples means reported at the ends of Tables 4 and 5 show that the subset of children under 2 years, and the total sample up to age 5 suffer diarrheal rates of $21.6 \%$ and $17 \%$ respectively. As shown in Table 5 , younger children in general are more likely than older children to have experienced diarrhea during the past two weeks. Those younger than 12 months are particularly vulnerable, for whom each additional month of age is associated with a 0.9 percentage point increase in the likelihood of a recent diarrheal episode, a 5.3\% increase relative to the sample mean. For those between 12 months to 24 months, the association between age (in months) and the probability of recent diarrhea is lower, at 0.4 percentage points, while for those over 24 months, we find negative association of 0.1 percentage point. This curvilinear relationship between age and diarrhea is consistent across the specifications reported in Table 5. A similar relationship has been widely documented in other studies, both for diarrhea and growth faltering, and is generally understood to reflect the cessation of exclusive breastfeeding and the introduction of an increasingly diverse set of weaning foods during this period. A recent review estimated that $72 \%$ of deaths associated with diarrhea occur in the first two years of life and the highest rate of severe disease occurs between 6 and 24 months (Walker et al., 2013).

We find that children of older mothers are less likely to have had a recent episode of diarrhea compared to those with younger mothers, perhaps due to greater experience among older mothers, or higher socio-economic status. Each additional year of the mother's age is associated with a 0.3 to 0.4 percentage point decrease in the likelihood of diarrhea. While children of mothers who have completed primary or secondary school are no less likely experience diarrhea than those whose mothers have not completed primary school, diarrhea rates of children of mothers who have completed education beyond secondary school are significantly lower (estimates range from 4 to 7 percentage points depending on model specification; the most conservative specification of Table 5 corresponds to a $22 \%$ decrease in diarrheal episode likelihood relative to the sample mean). This tells us that while mother's education can be an important factor in predicting diarrheal likelihood among children, this is only true at high levels of education.

We illustrate the main findings of this analysis in the Figure 1, which shows the impacts of consuming high risk foods on the likelihood of diarrheal disease, based on the most conservatives specifications in Table 4 (columns 4 and 8). Exclusive breastfeeding - that is, not consuming any foods potentially contaminated with diarrheal pathogens - has a large negative effect on the probability of diarrhea. Children who were exclusively breastfed were 5.8 percentage points less likely to have experience diarrhea, a $27 \%$ reduction relative to the average diarrhea rate. 
On the other hand, children who had consumed milk, fish, selfish, or fruits in the past 24 hours, were more likely to have experienced diarrhea. We note that this does not imply that children's diets should be restricted to low-risk foods. The same foods that are likely to carry pathogens are also among the most nutritious. However, fresh foods must always be carefully washed and peeled or cooked to avoid foodborne disease.

Figure 1: Consuming high-risk foods increases the risk of diarrheal disease among children under 2 years

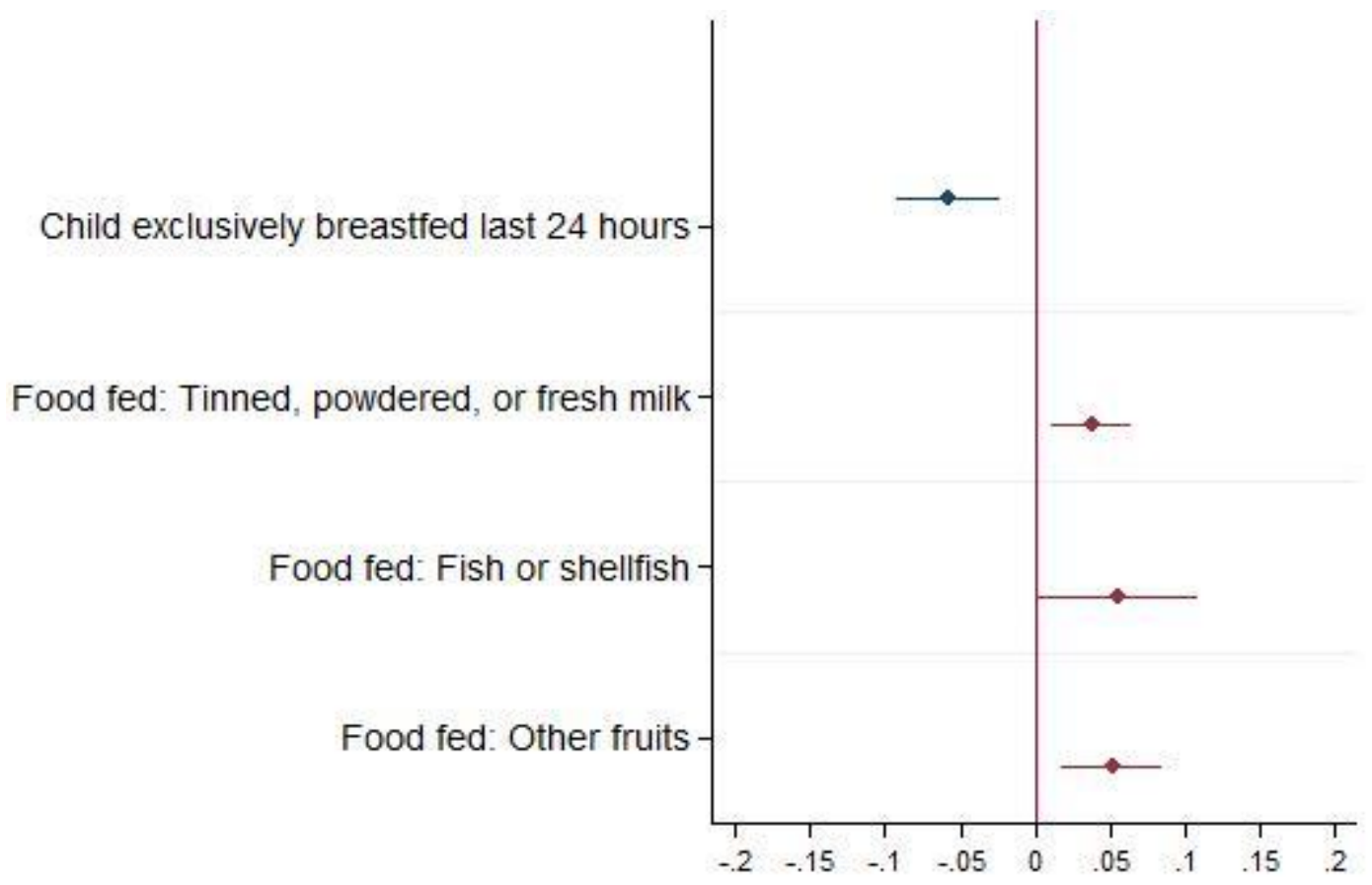


Table 4: Determinants of diarrhea for children under 2 years of age

\begin{tabular}{|c|c|c|c|c|c|c|c|c|}
\hline & (1) & (2) & (3) & (4) & (5) & (6) & (7) & (8) \\
\hline & \multicolumn{8}{|c|}{ Child had diarrhea in the last two weeks } \\
\hline \multicolumn{9}{|l|}{ Child's age } \\
\hline \multirow[t]{2}{*}{ Less than 12 months (inclusive) } & 0.008 & 0.009 & 0.008 & 0.009 & 0.012 & 0.012 & 0.012 & 0.012 \\
\hline & $(0.003)^{* * *}$ & $(0.003)^{* * *}$ & $(0.003)^{* * *}$ & $(0.003)^{* * *}$ & $(0.003)^{* * *}$ & $(0.003)^{* * *}$ & $(0.003)^{* * *}$ & $(0.003)^{* * *}$ \\
\hline \multirow[t]{2}{*}{12 months - 24 months (inclusive) } & 0.004 & 0.005 & 0.004 & 0.005 & 0.006 & 0.006 & 0.006 & 0.006 \\
\hline & $(0.001)^{* * *}$ & $(0.001)^{* * *}$ & $(0.001)^{* * *}$ & $(0.001)^{* * *}$ & $(0.002)^{* * *}$ & $(0.002)^{* * *}$ & $(0.002)^{* * *}$ & $(0.002)^{* * *}$ \\
\hline \multirow[t]{2}{*}{ Mother's age } & -0.004 & -0.004 & -0.004 & -0.004 & -0.004 & -0.004 & -0.004 & -0.004 \\
\hline & $(0.001)^{* * *}$ & $(0.001)^{* * *}$ & $(0.001)^{* * *}$ & $(0.001)^{* * *}$ & $(0.001)^{* * *}$ & $(0.001)^{* * *}$ & $(0.001)^{* * *}$ & $(0.001)^{* * *}$ \\
\hline \multicolumn{9}{|l|}{ Mother's education } \\
\hline \multirow[t]{2}{*}{ Primary } & 0.005 & -0.008 & 0.006 & -0.005 & 0.009 & -0.006 & 0.012 & -0.002 \\
\hline & $(0.022)$ & $(0.025)$ & $(0.023)$ & $(0.026)$ & $(0.022)$ & $(0.025)$ & $(0.024)$ & $(0.026)$ \\
\hline \multirow[t]{2}{*}{ Secondary } & -0.027 & -0.028 & -0.025 & -0.022 & -0.028 & -0.032 & -0.024 & -0.025 \\
\hline & $(0.026)$ & $(0.030)$ & $(0.028)$ & $(0.032)$ & $(0.027)$ & $(0.030)$ & $(0.029)$ & $(0.032)$ \\
\hline Higher & $\begin{array}{c}-0.061 \\
(0.032)^{*}\end{array}$ & $\begin{array}{c}-0.065 \\
(0.035)^{*}\end{array}$ & $\begin{array}{l}-0.059 \\
(0.037)\end{array}$ & $\begin{array}{l}-0.055 \\
(0.039)\end{array}$ & $\begin{array}{c}-0.070 \\
(0.032)^{* *}\end{array}$ & $\begin{array}{c}-0.071 \\
(0.035)^{* *}\end{array}$ & $\begin{array}{c}-0.063 \\
(0.037)^{*}\end{array}$ & $\begin{array}{l}-0.059 \\
(0.040)\end{array}$ \\
\hline
\end{tabular}


Table 4: Determinants of diarrheal rate for children under 2 years of age (continued)

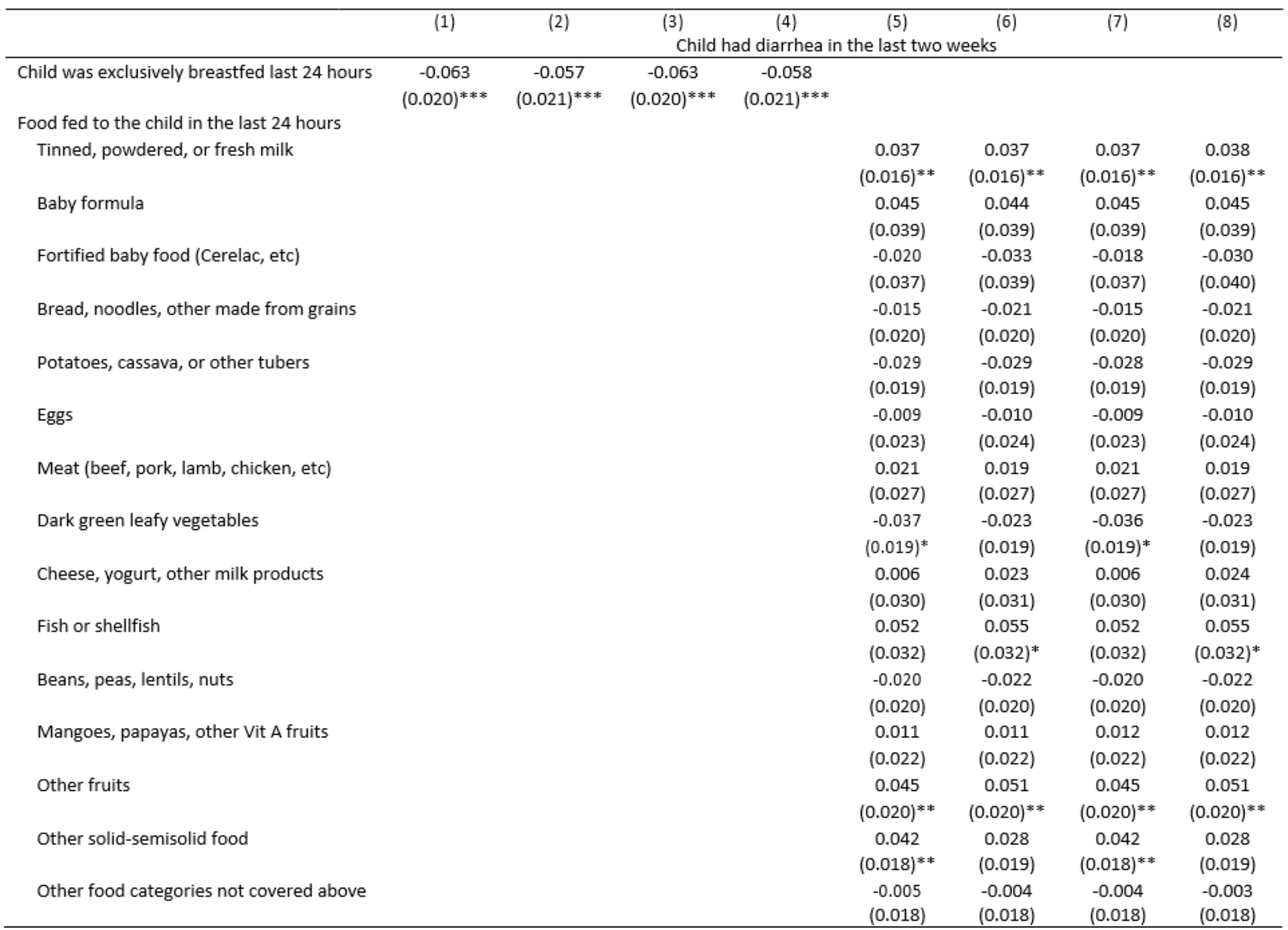


Table 4: Determinants of diarrheal rate for children under 2 years of age (continued)

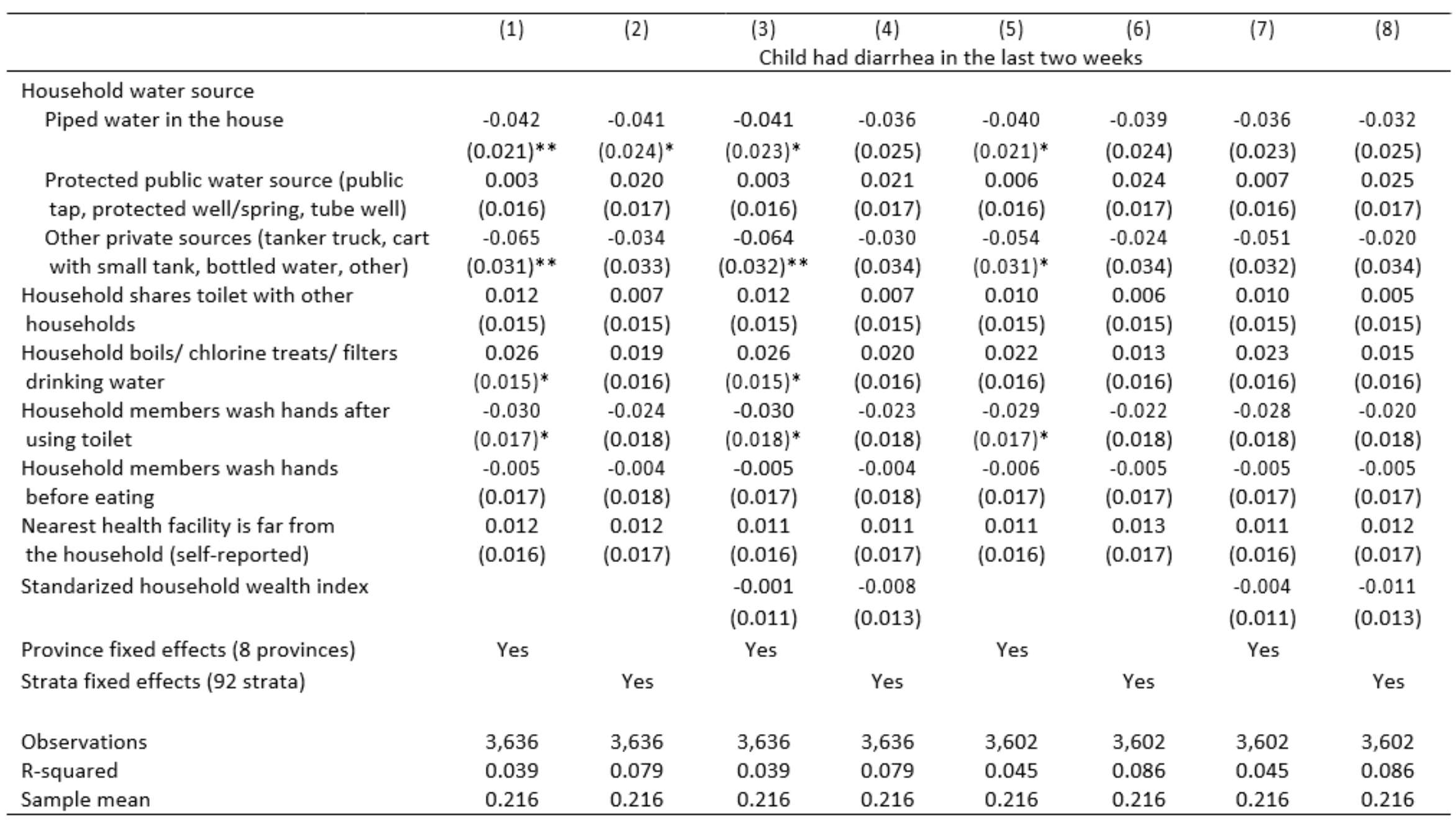

Note: Standard errors are clustered at the level of the primary sampling unit. *, **, and *** correspond to p-values less than $0.10,0.05$, and 0.01 respectively. Sample includes all the households with a child under 2 years of age. For those households with multiple children in the given age category, the information corresponds to the youngest living child. The reference dummy for mother's education is "not educated". The reference dummy for household water source is "Unprotected public water source (river, dam, spring, rain water, etc)." Strata is a composite of a county divided into its rural and urban parts. 


\section{Table 5: Determinants of diarrhea for children under 5 years of age}

Table 5: Determinants of diarrheal rate for children under 5 years of age

\begin{tabular}{|c|c|c|c|c|}
\hline & (1) & $(2)$ & (3) & (4) \\
\hline & \multicolumn{4}{|c|}{ Child had diarrhea in the last two weeks } \\
\hline \multirow[t]{2}{*}{ Age: Less than 12 months (inclusive) } & 0.009 & 0.009 & 0.009 & 0.009 \\
\hline & $(0.001)^{* * * *}$ & $(0.001)^{* * *}$ & $(0.001)^{* * *}$ & $(0.001)^{* * *}$ \\
\hline \multirow[t]{2}{*}{ Age: 12 months - 24 months (inclusive) } & 0.004 & 0.004 & 0.004 & 0.004 \\
\hline & $(0.001)^{* * *}$ & $(0.001)^{* * *}$ & $(0.001)^{* * *}$ & $(0.001)^{* * *}$ \\
\hline \multirow[t]{2}{*}{ Age: 24 months to 59 months (inclusive) } & -0.001 & -0.001 & -0.001 & -0.001 \\
\hline & $(0.000)^{* * *}$ & $(0.000)^{* * *}$ & $(0.000)^{* * *}$ & $(0.000)^{* * *}$ \\
\hline \multirow[t]{2}{*}{ Mother's age } & -0.003 & -0.003 & -0.003 & -0.003 \\
\hline & $(0.001)^{* * *}$ & $(0.000)^{* * *}$ & $(0.000)^{* * *}$ & $(0.000)^{* * *}$ \\
\hline \multirow[t]{2}{*}{ Mother's education: Primary } & 0.000 & -0.014 & 0.011 & -0.005 \\
\hline & $(0.011)$ & $(0.012)$ & {$[0.012)$} & {$[0.012]$} \\
\hline \multirow[t]{2}{*}{ Mother's education: Secondary } & -0.024 & -0.031 & -0.008 & -0.017 \\
\hline & $(0.013)^{*}$ & $(0.014)^{* *}$ & {$[0.014)$} & {$[0.014)$} \\
\hline \multirow[t]{2}{*}{ Mother's education: Higher } & -0.061 & -0.069 & -0.038 & -0.046 \\
\hline & $(0.015)^{* * * *}$ & $(0.016)^{* * *}$ & $(0.017)^{* *}$ & $(0.017)^{* * *}$ \\
\hline \multicolumn{5}{|l|}{ Household water source } \\
\hline \multirow[t]{2}{*}{ Piped water in the house } & -0.032 & -0.024 & -0.019 & -0.012 \\
\hline & $(0.010)^{* * *}$ & $(0.011)^{* *}$ & $(0.011)^{*}$ & {$[0.011)$} \\
\hline \multicolumn{5}{|l|}{ Protected public water source (public } \\
\hline tap, protected well/spring, tube well) & $\begin{array}{c}-0.011 \\
(0.008)\end{array}$ & $\begin{array}{c}0.001 \\
(0.009)\end{array}$ & $\begin{array}{l}-0.008 \\
(0.008)\end{array}$ & $\begin{array}{c}0.003 \\
(0.009)\end{array}$ \\
\hline $\begin{array}{l}\text { Other private sources (tanker truck, cart } \\
\text { with small tank, bottled water, other) }\end{array}$ & $\begin{array}{l}-0.023 \\
(0.016)\end{array}$ & $\begin{array}{l}-0.016 \\
(0.017)\end{array}$ & $\begin{array}{l}-0.012 \\
{[0.017)}\end{array}$ & $\begin{array}{l}-0.006 \\
(0.017)\end{array}$ \\
\hline $\begin{array}{l}\text { Household shares toilet with other } \\
\text { households }\end{array}$ & $\begin{array}{c}0.019 \\
(0.007)^{* * *}\end{array}$ & $\begin{array}{c}0.020 \\
(0.007)^{* * *}\end{array}$ & $\begin{array}{c}0.020 \\
(0.007)^{* * *}\end{array}$ & $\begin{array}{c}0.019 \\
(0.007)^{* * *}\end{array}$ \\
\hline $\begin{array}{l}\text { Household boils/ chlorine treats/ filters } \\
\text { drinking water }\end{array}$ & $\begin{array}{c}0.006 \\
(0.007)\end{array}$ & $\begin{array}{c}0.006 \\
(0.007)\end{array}$ & $\begin{array}{c}0.009 \\
(0.007)\end{array}$ & $\begin{array}{c}0.009 \\
(0.007)\end{array}$ \\
\hline $\begin{array}{l}\text { Household members wash hands after } \\
\text { using toilet }\end{array}$ & $\begin{array}{r}-0.016 \\
(0.010)\end{array}$ & $\begin{array}{l}-0.012 \\
(0.010)\end{array}$ & $\begin{array}{l}-0.013 \\
(0.010)\end{array}$ & $\begin{array}{r}-0.010 \\
(0.010)\end{array}$ \\
\hline $\begin{array}{l}\text { Household members wash hands } \\
\text { before eating }\end{array}$ & $\begin{array}{c}0.004 \\
(0.010)\end{array}$ & $\begin{array}{c}0.005 \\
(0.010)\end{array}$ & $\begin{array}{c}0.004 \\
(0.010)\end{array}$ & $\begin{array}{l}0.005 \\
(0.010)\end{array}$ \\
\hline $\begin{array}{l}\text { Nearest health facility is far from } \\
\text { the household (self-reported) }\end{array}$ & $\begin{array}{c}0.018 \\
(0.010)^{*}\end{array}$ & $\begin{array}{c}0.013 \\
(0.010)\end{array}$ & $\begin{array}{c}0.015 \\
(0.010)\end{array}$ & $\begin{array}{c}0.011 \\
(0.010)\end{array}$ \\
\hline \multirow[t]{2}{*}{ Standarized household wealth index } & & & -0.014 & -0.019 \\
\hline & & & $(0.005)^{* * *}$ & $(0.006)^{* * *}$ \\
\hline Province fixed effects (8 provinces) & Yes & & Yes & \\
\hline Strata fixed effects ( 92 strata) & & Yes & & Yes \\
\hline Observations & 14,033 & 14,033 & 14,033 & 14,033 \\
\hline R-squared & 0.045 & 0.062 & 0.046 & 0.063 \\
\hline Sample mean & 0.170 & 0.170 & 0.170 & 0.170 \\
\hline
\end{tabular}

Note: Standard errors are clustered at the level of the primary sampling unit. *, **, and *** correspond to p-values less than $0.10,0.05$, and 0.01 respectively. Sample includes all the households with a child under 5 years of age. For those households with multiple children in the given age category, the information corresponds to the youngest living child. The reference dummy for mother's education is "not educated". The reference dummy for household water source is "Unprotected public water source (river, dam, spring, rain water, etc)." Strata is a composite of a county divided into its rural and urban parts. 


\section{Household characteristics:}

We next look at various household characteristics relevant to transmission of diarrheal pathogens. In Table 5, we find that using a shared toilet significantly increases the likelihood of diarrhea among children by around 2 percentage points (about $12 \%$ relative increase). While this effect is positive among the sub-sample of under 2 years, it is not significant, suggesting that the effect is driven by children who are old enough to use toilets themselves, rather than by transmission by other household members. Piped water access emerges as another important predictor. However, this effect weakens in magnitude and become less precisely estimated when comparisons are within-strata rather than within-region and when controlling for household wealth level. Similarly, the use of water from other private sources such as tanker trucks or bottled water is negatively correlated with diarrhea among children under 2 when omitting controls for household wealth and geographical strata, but absent when including these, and also absent when older children are included in the sample.

While household behaviours such as whether household members wash their hands after using the toilet or before eating, whether they treat drinking water in some way, and whether the health facility is far from the household, show signs in expected directions, the effects are not significant in most cases. Self-reported data on water treatment and hand-washing, which are known by many respondents to be 'good' behaviors, is notoriously prone to bias, and the lack of a significant relationship is thus not surprising. Household wealth level, while not significant among the sub-sample of younger children, is a significant predictor of diarrhea in the overall sample.

Household characteristics overall appear to be less important determinants of diarrheal disease among younger children but their importance, particularly that of access to an exclusive toilet facility and piped water, grow when older children included in the sample.

\section{Food sources:}

As can be seen from Table 4, exclusive breastfeeding significantly reduces the chances of diarrhea among children under 2 years. Children in this age group who were exclusively breastfed during the 24 hours before the survey were 6 percentage points less likely to have experienced diarrhea over the past 2 weeks than those whose diet included other foods, a 27 percent decrease relative to the sample mean. This effect is remarkably close to the estimate for Africa presented in Table 1 that 29 percent of diarrheal disease is foodborne

Consumption of cow's milk is the food most strongly associated with diarrhea, increasing the likelihood of diarrheal incidence by up to 3.8 percentage points (an 18 percent increase relative to the mean). Other research has shown that raw milk is more likely to be contaminated at point of purchase, but that even pasteurized and long-life milk are often contaminated with pathogens at the time these are consumed by infants (Simiyu et al., 2019). Fruits in general appear to be another significant source of diarrhea, associated with 4.5 percentage point increase in diarrheal likelihood (21.5 percent relative increase). Other food items that one would expect to increase diarrheal likelihood, such as meat and fish, show the expected signs of association. While the association with meat consumption is not estimated 
with sufficient statistical precision to rule out the absence of an effect once wealth controls are added, the association with consumption of fish remains significant at the $10 \%$ level.

In sum, for children under 2 years of age, we find that food are the factors most strongly associated with diarrheal disease, as opposed to mother's or household's characteristics. This highlights the importance of food safety for Kenya's youngest and thus most vulnerable children.

\section{The link between public investment food safety and FBD}

The global health burden of FBD exhibits a strong disparity across countries that tracks their level of economic development. Low- and middle-income countries (LMICs) in South Asia, Southeast Asia, and Sub-Saharan Africa account for 53 percent of all foodborne illnesses, 75 percent of FBD-related deaths, and 72 percent of FBD-related DALYs, while representing only about 41 percent of the global population (Jaffee et al., 2018). Gaps in public capacity to manage food safety risk, largely due to inadequate funding of crucial functions such as veterinary and meat inspection services, as well as a lack of trained personnel, and unenforceable regulations are some of the factors believed to explain this observed difference in food safety outcomes (ibid.)

Jaffee et al. describe a food safety life cycle, in which the economic burden of foodborne illness first increases with economic development as food production and marketing becomes more complex, and diets more varied, and then falls as public and private mechanisms for handling food safety risk evolve to manage food safety risk. This pattern is illustrated in Figure 1 below.

At low levels of economic development, poor hygienic conditions in wet markets and poor access to potable water are the primary food safety risks. However, foodborne illness is reduced somewhat by two factors. First, food is typically produced close to where it is consumed and is often produced by the consumer or sold directly from the producer to the consumer. This implies fewer opportunities for contamination, and less time for disease-causing organisms to multiply. Second, when incomes are low, diets primarily consist of relatively low-risk starchy staples.

As incomes grow, people tend to consume more animal-source foods and fresh produce. These are more nutritious, but area also more likely to harbor pathogens. Further, with economic development and regional specialization, food tends to travel longer distances, pass through a larger number of intermediaries, and is bulked in larger quantities, before reaching consumers. Each of these factors increases the risk of contamination with pathogens. Food fraud is also an increasing risk as food systems modernize. Food fraud includes the undeclared substitution of lower-value ingredients, and the addition of prohibited and potentially dangerous preservatives, coloring, or other non-food substances.

Once a country attains high-income status, food safety management systems typically catch up with the greater risks implied by a modernized food system, and the economic burden of FBD falls.

Kenya, as a lower-middle income country, is in the second phase of the food safety life cycle. The food system is transitioning out of traditional, village-based production and consumption as the share of the population living in urban centers grows, and diets are shifting toward higher-risk fresh produce 
(Tschirley et al., 2015). Meanwhile, funding for veterinary services, used as a benchmark for one aspect of food safety management capacity, remains 'inadequate', according to the World Organisation for Animal Health (OIE) ${ }^{6}$

Figure 2: The food safety life cycle by level of economic development. Reproduced with permission from Figure 1.2 in Jaffee et. al, 2018

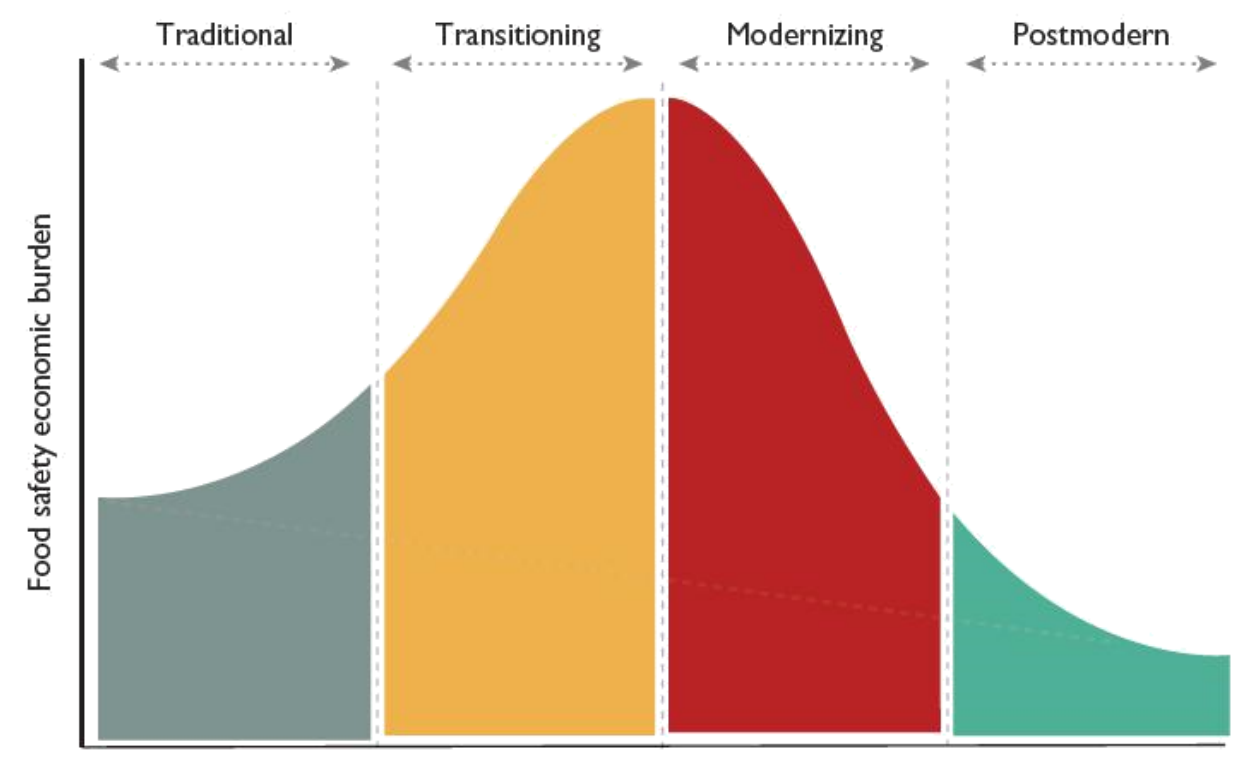

Level of economic development

While this life cycle analogy is useful for understanding broad patterns in the burden of FBD across countries, it is possible for countries at lower levels of development to achieve better outcomes through public investment in food safety capacity. This is demonstrated by Jaffee et al.'s analysis, which compares national levels of foodborne illness to food safety management capacity. The authors report that the burden of foodborne illness attributable to animal-source foods is lower in countries with higher values of animal products-related food safety capacity (correlation coefficient of $-0.57 ;$ p. 88). Middle-income countries, which typically have the highest foodborne disease burdens, also have the most to gain from better management of food safety risk. By prioritizing the management of food safety risk, such countries can transition more quickly toward the final stage of the food safety life cycle.

Of 35 low middle-income countries that have been assessed by the World Organisation for Animal Health for performance of veterinary services, only five were deemed to fund these services adequately. The average health burden of foodborne disease attributed to animal-source foods in these countries was 177.1 DALYs per 100,000 people, compared to 293.2 for the remaining 30 countries that failed to fund veterinary services adequately. Kenya scores roughly in the middle of sub-Saharan African countries in

\footnotetext{
${ }^{6}$ This can be inferred from Figure 3.7 in Jaffee et. al. (2018), which shows the health burden, in terms of disability-adjusted life years (DALYs) attributable to animal-source foods among sub-Saharan African countries, by funding
} 
terms of its capacity to manage food safety in animal-source foods. Considering its neighbors, Kenya ranks several places ahead of Tanzania, but far behind Uganda (Jaffee et al., 2018).

\section{Conclusions and policy implications}

The positive relationship between health outcomes and food safety investment documented elsewhere, and the stark disparities between the costs of FBD in Kenya and public investments to address this problem, particularly at the county level, suggest that both health and economic outcomes in Murang'a, Laikipia, Nakuru, Nyandarua, and Nairobi counties could be greatly improved through greater public investment in food safety management capacity.

Our analysis of the association between consumption of specific foods and diarrhea in young children indicates that food safety risk is particularly high in dairy products and fruits consumed raw. Public attention to improving the safety of these foods, both in supply chains and through improved household food handling, has the potential to pay dividends in terms of child health, with associated economic benefits of reduced private and public spending on health, increased caregiver time, and saved human capital.

Actions that can be taken immediately by county governments to improve food safety include the following:

- Provide or promote the provision of improved sanitation and hand-washing facilities (with soap) for use by food handlers, in hotels and markets where fresh food is sold, as well as upstream in the value chain (farm, packing house, wholesale market)

Educate farmers on the risks of using unclean water for irrigation and untreated manure as fertilizer

Offer pathogen testing of water bodies used for irrigation

Educate consumers on the 5 Keys to Safer Food. Materials are available from the WHO and can be displayed in health facilities, schools, and other public spaces. 


\section{Appendix}

Appendix Table 1: Formulas for calculations in Table 2

\begin{tabular}{|c|c|c|}
\hline (1) & (2) & (3) \\
\hline $\begin{array}{l}\text { Col Number } \\
\text { from Table } 2\end{array}$ & Column Title & Calculation \\
\hline Col 1 & $\begin{array}{l}\text { Child had diarrhea past } 2 \\
\text { weeks (\%) }\end{array}$ & \\
\hline $\mathrm{Col} 2$ & Number of obs. & \\
\hline $\mathrm{Col} 3$ & $\begin{array}{l}\text { Extrapolated \% of foodborne } \\
\text { diarrhea / } 2 \text { weeks }\end{array}$ & $\begin{array}{l}\text { Col } 1 \text { X Proportion of all diarrheal disease that is } \\
\text { food-borne }\end{array}$ \\
\hline $\mathrm{Col} 4$ & $\begin{array}{l}\text { Extrapolated diarrheal child } \\
\text { deaths / year / } 1000\end{array}$ & $\begin{array}{l}\text { Kenyan rate of child deaths per } 1000 \text { live births } \mathrm{X} \\
\text { (County-level diarrheal rate from Col 1/Kenya-wide } \\
\text { diarrheal rate from Col 1) }\end{array}$ \\
\hline Col 5 & $\begin{array}{l}\text { County population, } 2018 \\
\text { (CIDPs) }\end{array}$ & \\
\hline $\mathrm{Col} 6$ & $\begin{array}{l}\text { County population under } 5 \\
\text { (CIDPs) }\end{array}$ & \\
\hline \multirow[t]{2}{*}{$\mathrm{Col} 7$} & $\begin{array}{l}\text { Annual under- } 5 \text { deaths due } \\
\text { to diarrheal FBD }\end{array}$ & $\begin{array}{l}\text { Kenyan rate of annual under- } 5 \text { deaths due to FBD X } \\
\text { (County population under } 5 \text { from Col } 6 / \text { Kenya's } \\
\text { population under } 5 \text { from Col } 6 \text { ) X (County-level } \\
\text { percent of foodborne diarrhea per } 2 \text { weeks from Col }\end{array}$ \\
\hline & & $\begin{array}{l}3 \text { / Kenya-wide percent of foodborne diarrhea per } 2 \\
\text { weeks from } \mathrm{Col} 3 \text { ) }\end{array}$ \\
\hline $\mathrm{Col} 8$ & $\begin{array}{l}\text { Estimated total DALYs due to } \\
\text { FBD }\end{array}$ & $\begin{array}{l}\text { DALYs per } 100,000 \text { due to FBD X County population/ } \\
100000\end{array}$ \\
\hline $\mathrm{Col} 9$ & $\begin{array}{l}\text { Estimated annual cost of } \\
\text { FBD (million KSH) }\end{array}$ & $\begin{array}{l}\text { County level total DALYs due to FBD from Col } 8 X \\
\text { County level GDP per capita in KSH / } 1000000\end{array}$ \\
\hline Col 10 & $\begin{array}{l}\text { Loss as a } \% \text { of county or } \\
\text { national GDP }\end{array}$ & $\begin{array}{l}100 \times \text { (Estimated annual cost of FBD from Col } 9 X \\
1000000) / \text { County-level GDP }\end{array}$ \\
\hline Col 11 & \% stunted children & \\
\hline
\end{tabular}




\section{ABOUT THE AUTHORS}

\section{Vivian Hoffmann is a Research Fellow at International Food Policy Research Institute's Markets, Trade and Institutions Division.}
Siddhartha Baral was a Research Analyst at International Food Policy Research Institute's Markets, Trade and Institutions Division and is currently pursuing a PhD at the University of California San Di- ego.

\section{ACKNOWLEDGMENTS}

\section{Funding for this work was provided by the Dutch Ministry of Foreign Affairs through SNV (Netherlands Development Organization).}

\section{REFERENCES}

Grace, D., Alonso, S., Lulietto, M., Kebede, A., Lindahl, J., Mader, R., Madukeh, V., et al. (2018). Food Safety Systems Performance Assessment Tool: Results for Sub-Saharan Africa. Nairobi: International Livestock Research Institute.

Guthiga, P., Kirui, L., and Karugia, J. (2019) Budget Data for Dairy and Horticulture Food Safety-Kenya-Apr 12, 2019. Obtained from the authors.

Hassouneh, I., Radwan, A., Serra, T., \& Gil, J. M. (2012). Food scare crises and developing countries: the impact of avian influenza on vertical price transmission in the Egyptian poultry sector. Food policy, 37(3), 264-274.

Havelaar, A. H., Kirk, M. D., Torgerson, P. R., Gibb, H. J., Hald, T., Lake, R. J., .. \& Speybroeck, N. (2015). World Health Organization global estimates and regional comparisons of the burden of foodborne disease in 2010. PLoS medicine, 12(12), e1001923.

Jaffee, S., Henson, S., Unnevehr, L., Grace, D. and Cassou, E., 2018. The Safe Food Imperative: Accelerating Progress in Low-and MiddleIncome Countries. The World Bank.

Kavle, J. A., El-Zanaty, F., Landry, M., \& Galloway, R. (2015). The rise in stunting in relation to avian influenza and food consumption patterns in Lower Egypt in comparison to Upper Egypt: results from 2005 and 2008 Demographic and Health Surveys. BMC public health, 15(1), 285.

Kenya National Bureau of Statistics. (2010). The 2009 Kenya population and housing census (Vol. 1). Kenya National Bureau of Statistics, Nairobi.

Kenya National Bureau of Statistics. (2015). Kenya Demographic and Health Survey 2014. Kenya National Bureau of Statistics, Nairobi.

Kenya National Bureau of Statistics. (2019). Economic Survey 2019. Kenya National Bureau of Statistics, Nairobi.

Popovic, R., Radovanov, B., \& Dunn, J. W. (2017). Food scare crisis: the effect on Serbian dairy market. International Food and Agribusiness Management Review, 20(1), 113-127.

Simiyu, S., J. Mumma, O. Cumming, V. Hoffmann, M.H. Tsai, and K. Baker. (2019) Milk safety at the vendor and household level: Evidence from peri-urban Kisumu. IFPRI report.

Tschirley, D., Reardon, T., Dolislager, M. and Snyder, J., 2015. The rise of a middle class in East and Southern Africa: Implications for food system transformation. Journal of International Development, 27(5), pp.628-646.

UNICEF, 2018. "Estimates of child cause of death, Diarrhoea 2018." Retrieved from https://data.unicef.org/topic/child-health/diarrhoealdisease/

Walker, C. L. F., Rudan, I., Liu, L., Nair, H., Theodoratou, E., Bhutta, Z. A., ... \& Black, R. E. (2013). Global burden of childhood pneumonia and diarrhoea. The Lancet, 381(9875), 1405-1416.

Wankuru, P. (2019, May 2). For the first time, the relative economic size of Kenya's counties is clear [Blog Post]. Retrieved from https://blogs.worldbank.org/africacan/for-the-first-time-the-relative-economic-size-of-kenyas-counties-is-clear

World Health Organization. (2015). WHO estimates of the global burden of foodborne diseases:

foodborne disease burden epidemiology reference group 2007-2015 (No. 9789241565165). World Health Organization 
Funding for this work was provided by the Dutch Ministry of Foreign Affairs through SNV (Netherlands Development Organization). This publication has been prepared as an output of the Voices for Change Partnership and has not been independently peer reviewed. Any opinions expressed here belong to the author(s) and are not necessarily representative of or endorsed by IFPRI.

\section{INTERNATIONAL FOOD POLICY RESEARCH INSTITUTE}

A world free of hunger and malnutrition 